\title{
El IEAL y el Derecho Administrativo Económico
}

\author{
Jaime Rodríguez-Arana \\ Presidente de la Asociación Española de Ciencias Administrativas
}

SUMARIO: I. EL IEAL Y EL PROFESOR SEBASTIÁN MARTÍN-RETORTILLO. II. SEBASTIÁN MARTÍN-RETORTILLO Y EL DERECHO ADMINISTRATIVO ECONÓMICO.

\section{EL IEAL Y EL PROFESOR SEBASTIÁN MARTÍN-RETORTILLO*}

Hoy, este Salón de Actos «José Posada Herrera» del Instituto Nacional de Administración Pública, se viste con sus mejores galas para acoger un acto académico de singular transcendencia en la historia de esta Institución, como es el merecido recuerdo del profesor Sebastián MARTíN-Retortillo BAQuer, de quien esta casa y especialmente el Centro de Estudios Locales será deudor permanente de su dirección y sus enseñanzas.

Hemos escuchado ya palabras justas y certeras en honor de quien, durante los difíciles años de la Transición política a la democracia en España, ocupó con gran acierto la dirección del Instituto de Estudios de Administración Local, hoy integrado en esta Casa.

Ha intervenido el titular de la Cartera Ministerial — Rodolfo MARTín ViLla - que le confirió tal cargo de confianza, su maestro -Eduardo GARCÍA DE ENTERRÍA- su propio hermano Lorenzo y uno de los principales discípulos - Luis Cosculluela-, que pocos años más tarde le sucedió en la misma responsabilidad. Todos han glosado amplia y generosamente sus méritos intelectuales, así como sus servicios al bien común. En mi caso, me van a permitir que, en nombre de todos los que han estado al frente de este Instituto y de sus funcionarios me refiera a los dos años que el profesor MARTín-RETORTILlo ejerció la dirección del antiguo Instituto de Estudios de Administración Local, cuya tradición y funciones hoy asume el Centro de Estudios Locales del INAP.

\footnotetext{
* El texto de este epígrafe coincide con mi intervención en el acto académico que el INAP organizó el 22 de enero de 2002 en homenaje del que fuera Director del IEAL, profesor Sebastián MARTíN-RETORTILLO.
} 
La llegada de Sebastián Martín-Retortillo al Instituto, como es bien sabido, se produjo después de las primeras elecciones democráticas celebradas en España en junio de 1977, por lo que bien puede decirse que fue el primer Director del organismo de la restaurada democracia que se abría paso firme y seguro, pese a las dificultades, en la España de finales de los setenta.

En un reciente libro editado por esta casa El INAP cuarenta años de historia, Sebastián MarTín-Retortillo nos dejó, con su riguroso estilo habitual, las impresiones y testimonios de su paso por el Instituto de Estudios de Administración Local, por lo que podría resultar osado que en este momento, tras lo escuchado, tratase ahora de reproducir sus comentarios. Sin embargo, cuando una personalidad de la talla intelectual del profesor MARTín-RETORTILlo ocupa la dirección de un organismo de las características del Instituto de Estudios de Administración Local, es inevitable que su paso deje una huella que, pese al tiempo transcurrido, un cuarto de siglo, permanece presente en la vida de la Institución.

Esta percepción ha sido confirmada por algunos de los colaboradores del profesor MarTín-Retortillo en el IEAL, en su día objeto de su confianza y aprecio y que hoy comparten los mismos afectos con el actual Director. Confieso que lo que sigue a continuación pertenece a la tradición de esta Casa, sobre todo en el ámbito del Centro de Estudios Locales.

Por ejemplo, podemos recordar la adscripción al Instituto de la Residencia de Peñíscola en Castellón, formalizada en mayo de 1978 y que en la actualidad forma parte del conjunto de centros del Instituto Nacional de Administración Pública en los que se continúan realizando actividades docentes y formativas dirigidas a los funcionarios.

Tampoco hemos de olvidar el cambio producido en el régimen financiero del organismo, que supuso su transformación en un Organismo Autónomo de carácter administrativo una vez agotado el modelo de financiación del IEAL, inalterado desde sus orígenes y que estaba constituido por las cuotas obligatorias de las Corporaciones Locales, cuya continuidad se hacía problemática al existir un convencimiento pleno de que la autonomía municipal era algo más que una declaración de principios.

Ante la escasa viabilidad del futuro, Sebastián MarTín-Retortillo, con gran sentido de la realidad, hizo lo posible para que en el Real Decreto 2356 de 1 de diciembre de 1978, que modificó la estructura de diversos Centros directivos del Ministerio, se tuviese en cuenta esta situación, por lo que el citado Real Decreto dispuso que a partir del uno de enero de 1979 
el sostenimiento del IEAL lo fuese con cargo a los Presupuestos Generales del Estado.

Se cuenta entre sus más cercanos colaboradores de entonces que a su marcha estaría «ligero de equipaje como los hijos de la mar» y así sucedió pues tuvo especial empeño en que todos sus papeles y borradores de los múltiples trabajos que realizó durante su permanencia al frente de la Institución, tanto con motivo del proyecto de Constitución, como otras colaboraciones, dictámenes o informes sobre diversas materias legislativas de la Transición, quedasen depositadas en la Biblioteca del Instituto, donde aún se conservan y se pueden consultar por los investigadores.

Me resulta grato recordar a este respecto que uno de sus puntos de atención en el Instituto, como todos sabemos, fue la Biblioteca, a la que dotó de suficiencia presupuestaria, impulsó y fomentó en consonancia con su talante ilustrado y regeneracionista. En relación con el ámbito de la difusión documental de los libros especializados desempeñó quizás su papel más perdurable, pues mantuvo las colecciones que por entonces existían: Nuevo Urbanismo, que iniciada en 1970, alcanzaría en 1985 los cuarenta títulos, o los de Protección Ambiental, traducciones de libros clave en un momento en que comenzaba en España a tomarse conciencia de los graves desafíos ambientales a los que debía hacerse frente con todos los medios a nuestro alcance. Iniciativa suya fue la edición facsímil de la obra de Jerónimo Castillo de Bovadilla Política de Corregidores y Señores de Vasallos, magna aportación al conocimiento de la Historia del Derecho español escrita a fines del siglo xvi. También hemos de recordar la obra realizada bajo su dirección, con la colaboración de dos autores presentes en esta solemne sesión, el profesor Luis Cosculluela MonTaner y Enrique ORduña Rebollo, titulada Autonomías Regionales en España.

Sin embargo, bien puede decirse que la aportación editorial más importante de Sebastián Martín-Retortillo en el Instituto de Estudios de Administración Local fue, quizá, la Colección Administración y Ciudadano, que alcanzó 18 volúmenes en el corto espacio de dos años, empresa en la que colaboró activamente otro buen amigo Gregorio Burgueño. Para comprender el empeño del profesor MARTín-RETORTILLO en esta colección hemos de remitirnos al conocimiento de alguno de los principios que animaban su tarea y a magnas cualidades que habían forjado su personalidad y su ánimo, algunas de las cuales se han mencionado muy acertadamente esta tarde por los que le conocieron más de cerca. En primer lugar su origen aragonés y su educación familiar le permitieron un conocimiento directo e inmediato de la obra regeneracionista, principalmente la de Joaquín Costa, complementada después por sus estudios sobre temas de 
aguas y regadíos sobre las que, como todos sabemos, llegó a ser una de las primeras autoridades españolas en la materia.

Pero además entre sus grandes preocupaciones estaba el hombre, la persona humana, por lo que podía afirmar en su presentación a la citada Colección «Administración y Ciudadano» que «nos preocupan también, todos y cada uno de los problemas del ciudadano, del vecino». Este interés por la búsqueda del bienestar para el hombre marcará definitivamente su obra a lo largo de los años, bienestar que no se limitó sólo a una manifestación puramente material, sino a algo más profundo y espiritual, muy presente en toda su vida.

Volviendo al contenido de Administración y Ciudadano, Sebastián Martín-RetoRTILlo pensó que era necesario recuperar lo antiguo en permanente equilibrio con lo nuevo, pues sabido es que muchos problemas de entonces y de hoy existen tanto en nuestra historia como en otras latitudes y territorios. También era consciente de que no estábamos ante ninguna solución global para «vitalizar ante lo público la conciencia ciudadana de nuestro momento", otra vez el referente costista, por lo que abogaba porque las obligadas y lógicas tensiones Administración-ciudadano se resolviesen siempre en términos de convivencia. Para ello partía de tres fuentes inspiradoras de la Colección: la experiencia histórica, los estudios de política administrativa y la expresión que la preocupación por el hombre tenía en aquel momento.

Con estas variables impulsó una Serie de gran interés en la que junto a temas de estricta Historia de la Administración y sobre todo del Municipio, aparecieron otras del regeneracionismo de Macías PiCAVEA, Julio SENADOR Gómez o el propio Costa, junto a los estudios contemporáneos constitucionales o administrativos. El rigor de las obras seleccionadas se incrementó con la redacción de estudios preliminares a cargo de significados escritores, intelectuales, políticos o juristas de reconocido prestigio, entre los que se puede citar, sin ánimo de ser exhaustivo, entre otros, a José Jiménez Lozano, Justino de Azcárate, Francisco Tomás y Valiente, Alejandro Nieto, Juan Alfonso Santamaría Pastor, José Bermejo Vera, Florentino Agustín Díez González, Federico Carlos SAInz de Robles, Nicolás Pérez Serrano, Alfonso María Guilarte, etc., etc., etc.

Otro capítulo que es preciso mencionar fue el de las personas que durante aquellos dos años colaboraron de forma directa e inmediata con sus actividades, además de todos los funcionarios que en aquel momento prestaban sus servicios en el Instituto, como Ángel BaLLESTERos, Mario Corella, Juan D'Anjou, Domínguez Alcahud y los ya mencionados Ordu- 
Ña y Burgueño. Además, he de referirme a Francisco Perales Madueño y José MARTín CRESPo que se incorporaron entonces al Centro de Estudios Urbanos, o a Federico Carlos SAINZ DE RoBLES, ya magistrado del Tribunal Supremo, que dirigió una serie de jurisprudencia urbanística. Un magnífico plantel humano que facilitaba llevar a buen puerto la nave del Instituto, hacer realidad los proyectos y cumplir los objetivos.

Muy estimada doña Teresa, queridos colegas presentes en el acto, señoras y señores. Mi intervención está superando el tiempo previsto, por lo que pido mis disculpas. Pero antes de terminar quisiera hacer una última reflexión sobre la presencia de Sebastián MARTín-RETORTILlo en el Instituto de Estudios de Administración Local, que no pretende que sea sólo una justa alabanza de sus muchos méritos académicos, ya convenientemente realizada por los profesores que me han precedido en el uso de la palabra, ni de subrayar su decisiva dedicación al servicio del Estado, primero como Subsecretario del Ministerio de Educación y Ciencia, después en el Instituto, luego como Ministro Adjunto para la Administración Pública, o en su ejercicio de Diputado por la provincia de Huesca.

Estas palabras y otras pronunciadas en anteriores ocasiones, han aliviado, si se puede hablar así, el dolor de su mujer, de sus hijos, de su familia, o el sentimiento de amigos, compañeros y colaboradores, pero no han podido suplir por mal que nos pese su presencia. Por eso y para terminar, me parece oportuno recordar aquellos versos que MANRIQUE dedicaba a la fama y al buen nombre:

«No se os haga tan amarga
la batalla temerosa
que esperais
pues otra vida más larga
de fama tan gloriosa
aca dexáis;
aunque esta vida de honor
tampoco es eternal
ni verdadera,
más con todo es muy mejor
que la otra temporal
perecedera».

\section{SEBASTIÁN MARTÍN-RETORTILLO Y EL DERECHO ADMINISTRATIVO ECONÓMICO}

Como es sabido, la presencia de la Administración pública en la esfera económica coincide en buena medida con la crisis económica provocada 
por la Segunda Guerra Mundial en la que la iniciativa privada había quedado diezmada y era necesario iniciar una etapa de reconstrucción nacional. Sin embargo, es tras la Primera Guerra Mundial cuando surge como algo con consistencia la aproximación jurídico-económica que hoy ha cobrado tanta fuerza ${ }^{1}$ y que, en cualquier caso, constituye una dimensión relevante de la Ciencia Jurídica.

Ciertamente, la presencia de los poderes públicos en el entorno económico ha propiciado un acercamiento entre Derecho y Economía pues, como señalara hace ya tiempo MeILÁn GIL, la vocación de nuestro tiempo mucho tiene que ver, como es obvio, con la Economía ${ }^{2}$. Sin embargo, esa estrecha relación entre Derecho y Economía difícilmente introduce criterios de jerarquía entre ambas Ciencias. Simplemente, la realidad, ha forzado una suerte de relación que hace que una Ciencia y otra, hoy por hoy, sean complementarias. En este sentido, las formas jurídicas, y buen ejemplo de ello es la historia de la empresa pública, son utilizadas para alcanzar las mayores cotas de satisfacción pública; es decir, para un mejor gobierno de la Economía que siempre ha de llevar consigo, entre otras cosas, un más solidario reparto de los recursos existentes. Una vez más, es el marco del pensamiento abierto, complementario y compatible el que ofrece más posibilidades y, en mi opinión, refleja mejor la realidad.

Hoy, junto a un claro fenómeno de «privatización de lo colectivo» todavía coexiste, como es lógico, una cierta «publicitación de lo económico». ¿Por qué? Sencillamente porque en un Estado social y democrático de Derecho avanzado, las instituciones jurídico-privadas, que se mueven en un proceso de intercomunicación entre lo público y lo social, incorporan intereses colectivos, cuya disposición excede a las reglas propias del Derecho privado, como son las de la autonomía de la voluntad. En este ambiente es donde cuaja esa utilización por parte de la Administración del Derecho privado, siempre en el marco de una actividad administrativa al servicio de los intereses generales. El artículo 103 de la Constitución habla del sometimiento de la Administración al Derecho, sea público o privado. Lo importante es que, si actúa la Administración con sujeción al Derecho privado, se respete un núcleo básico público que siempre acompaña a la Administración pública.

Una de las razones de la extensión del Derecho privado a la actividad económica de la Administración puede encontrarse en la inadaptación del

\footnotetext{
${ }^{1}$ M. Franch i SAguer, Intervención administrativa sobre Bancos y Cajas de Ahorros, Madrid, Civitas, 1992, p. 25.

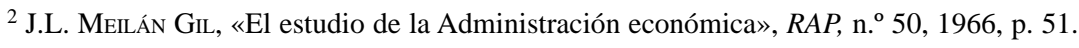


Derecho administrativo a alguna de las nuevas funciones que debe desarrollar la propia Administración en el campo económico ${ }^{3}$, ya que durante buena parte del siglo XIX la actividad administrativa de contenido económico se circunscribió a un uso masivo de la concesión por entender que su funcionalidad residía, hoy reaparece claramente esta aproximación, en tareas de impulso y coordinación. Y es precisamente el reconocimiento de la iniciativa pública económica y la asunción de responsabilidades en relación con el funcionamiento global del sistema económico, lo que explica esa necesidad de gestionar intereses colectivos de contenido económico. Por eso, lógicamente, la Administración utiliza las elaboraciones jurídicas del Derecho de la empresa y, por eso, algunos autores comenzaron a hablar de «Derecho económico como Derecho común a sujetos públicos y privados ${ }^{4}$. La aplicación del concepto de empresa y empresario a la empresa pública en sus distintas formas, la utilización de formas organizativas típicamente privadas por parte del sector público empresarial, la aplicación del Derecho de grupos al sector público, etc., son realidades que parecen justificar esa idea de un Derecho económico común a sujetos públicos y privados. Sin embargo, esta tesis no debe predicarse sin matizaciones pues la actividad administrativa, aunque actúe bajo forma jurídico-privada, jamás puede desprenderse de esa esencia pública que implica siempre sometimiento a los principios básicos de su condición de Administración pública.

También la doctrina ha intentado diferenciar los conceptos de Derecho de la Economía y Derecho económico. El primero haría referencia al conjunto de las normas jurídicas con contenido económico, mientras que el segundo, más bien, aludiría al conjunto de normas jurídicas a que tienden a asegurar, en un momento y en una sociedad determinada, el equilibrio entre los intereses particulares, los públicos y el interés económico ${ }^{5}$.

Es sabido que, en esta materia, el magisterio y las enseñanzas de Sebastián Martín-Retortillo han brillado con luz propia. Por ello, me parece pertinente traer a colación algunas opiniones del profesor MARTín-RETORTILLO que, aunque largas, simplifican la tarea:

En efecto. La consecuencia económica de la actividad administrativa ha sido puesta de relieve por el profesor MARTín-Retortillo:

\footnotetext{
${ }^{3}$ E. Alonso Ureba, La Empresa pública, Madrid, 1984, p. 503.

${ }^{4}$ Vid. A. Laudabère/P. Devolvé, Droit Public Economique, LGDJ, París, 1983, p. 6 y E. Alonso UREBA, op. cit., p. 505.
}

${ }^{5}$ M. Franch i Saguer, op. cit., p. 27. 
«Una cuestión previa a señalar. Se trata de recordar el alcance y las consecuencias económicas que siempre tiene toda, absolutamente toda, la actividad administrativa. J.L. Villar Palasí ha venido poniendo de relieve con marcada insistencia el condicionamiento financiero o, más exactamente, presupuestario de cualquier actuación de la Administración pública. El art. 43 de la LGP, entre otros, es en tal sentido expresivo por demás. Justicia, defensa, sanidad, educación, servicio exterior, cultura, seguridad ciudadana, medio ambiente, correos y un largo etcétera, son ámbitos, entre otros, a los que es referible la actuación de las Administraciones públicas. (...) No cabe prescindir de tales consideraciones. De todos modos, y resulta fácil advertirlo, no es a esta técnica a la que se refiere el contenido, siempre convencional del Derecho administrativo económico. El fenómeno señalado - condicionamiento y consecuencias económicas de toda la actuación administrativa- es preciso diferenciarlo del que ofrece la intervención y participación directa de la Administración en la propia actividad económica. Es a este último al que se concreta el contenido del Derecho administrativo económico. Perspectiva fundamentalmente pragmática, que se remite a una actividad objetivamente considerada, la económica (M.S. GianNinI), y que se asume sin pretensión alguna de plantear, ni menos aun postular, reconocimiento alguno de autonomía científica o académica de ningún tipo.» ${ }^{6}$

Además, en los tiempos que corren, el impacto en lo jurídico-administrativo de lo político y económico es evidente:

«En todo ello hay gran parte de verdad. El impacto en el sistema jurídico-administrativo de criterios principalmente derivados de la realidad política y económica, resulta de una obviedad manifiesta. tal situación, sin embargo, debe asumirse con extrema cautela y con un cierto relativismo. Y en cualquier caso no permite formalizar las consecuencias que se alcanzan. Dígase lo que se quiera, en buena parte, sigue siendo todavía válida la clásica observación de O. MAYER de que «La Constitución pasa y la Administración permanece». Permanencia, consecuentemente, de buena parte de las instituciones jurídico administrativas. Junto a ello hay también razones mucho más profundas, que afectan incluso a la realidad misma del Derecho y que es obligado considerar: las instituciones jurídicas, todas y siempre son resultado de un proceso histórico. En él van decantándose sus rasgos; se rechazan unos perfiles, al mismo tiempo que se asumen otros distintos. «La realidad social del tiempo en que han de ser aplicadas», en los términos mismos que señala el art. 3.1CC — la interpretación involutiva del propio ordenamiento, como recogiera Santi RoMANO-, introduce siempre en todas las instituciones jurídicas un innegable elemento de tensión que las dota de un carácter eminentemente dinámico. Aquellas tienen, deben tener en sí mismas, perceptibilidad bastante para captar y asumir las exigencias que impone su propia evolución. De ahí que asumidas estas exigencias, no quepa arrumbar sin más el sistema institucional vigente. Es preciso afirmar su permanencia. Lo que por el contrario se requiere es que se plantee de forma que tenga permeabilidad bastante para captar la realidad, siempre variable, que debe ordenar, no proclamar su arrumbamiento.» ${ }^{7}$

En realidad, la presencia de la Administración en la economía ha justificado la existencia de un Derecho Público de la Economía que ha sido

\footnotetext{
${ }^{6}$ S. Martín-Retortillo, Derecho Administrativo Económico I, Madrid, 1988, pp. 52-53.

${ }^{7}$ S. Martín-Retortillo, op. cit., pp. 54-55.
} 
definido por el profesor Martín Mateo como el Derecho que impone u orienta las conductas de los agentes económicos en el sentido comunitariamente relevante. Supone, desde luego, dice Martín Mateo, el motor y, a la vez, la legitimación de la Administración económica ${ }^{8}$. Sin embargo, esta rama del Derecho público no se agota en lo que es propiamente gestión o mediatización pública de la Economía, sino que hay un componente social indudable ${ }^{9}$ que es, en mi opinión, esa ordenación de las relaciones sociales hacia la justicia, que, como es lógico, tiene mucho que ver con los objetivos y criterios constitucionales. En este sentido, la Administración vela, no solo porque las actividades industriales se realicen en unas condiciones de seguridad y sanidad aceptables, sino que debe cuidar de que las empresas más significativas tengan características idóneas y sean capaces de funcionar con eficacia. ${ }^{10}$ Además, el profesor MARTín MATEO también subraya una propiedad del moderno Derecho público económico que resulta especialmente relevante, pues no se puede olvidar que estamos en un Estado social de Derecho en el que la Administración pública no detenta ya monopolísticamente el interés público, sino que éste, tal y como ha declarado el Tribunal Constitucional, se define a través de una acción combinada entre Estado y Sociedad. De ahí que se entienda perfectamente que a la tradicional defensa de los trabajadores que los poderes públicos asumen una vez superados los inicios de la industrialización, se suman ahora una serie de acciones destinada a proteger a los consumidores, a los usuarios de los servicios (...), a los clientes con menor capacidad negociadora... ${ }^{11}$.

El Derecho público económico surge, pues, con la crisis del primer liberalismo y con la asunción por parte del Estado de un papel relevante en la dirección del sector privado en el ámbito económico y de los sectores públicos industriales y comerciales. La presencia pública en la economía aumenta notablemente tras la Segunda Guerra Mundial: es cuando el Estado asume la dirección del crédito y comienza a funcionar como banquero. Hoy, sin embargo, más que el mantenimiento de la presencia administrativa en la economía, el Derecho público económico se orienta, como señala Franch i SAGUER, a la consecución de una determinada política económica. ${ }^{12}$ Esta aproximación debe, finalmente, ponerse e relación

\footnotetext{
${ }^{8}$ R. Martín Mateo, Derecho Público de la Economía, Madrid, 1985, p. 19.

${ }^{9}$ Ibidem.

${ }^{10}$ R. Martín Mateo, op. cit., p. 20.

11 Ibidem.

${ }^{12}$ M. Franch i Saguer, op. cit., p. 33 y bibliografía allí citada.
} 
con los objetivos constitucionales y muy singularmente con la funcionalidad de los poderes públicos en un Estado social de Derecho de fines del siglo xx.

El Derecho administrativo económico tiene como elemento clave la actividad administrativa o pública en el entorno económico. Es más, el ámbito de lo económico a lo principal, no tanto la presencia de la Administración pública. Lo económico, por tanto, adquiere una especial significación.

La presencia de la Administración en la vida económica introduce importantes modificaciones en la estructura administrativa. Es más, el concepto de Administración económica se refiere propiamente a aquel sector de la Administración pública que actúa en el campo de la intervención en la economía y de la prestación y producción de bienes económi$\cos ^{13}$. Desde un punto de vista estático, de acuerdo con Martín Mateo, la Administración económica se refiere a la organización y los medios de que disponen los entes públicos para incidir en el curso de la vida económica. Desde una perspectiva dinámica, la Administración económica se refiere al conjunto de decisiones adoptadas para conseguir determinados propósitos de índole económica.

Esa perspectiva dinámica ha sido puesto de manifiesto por el profesor Martín-Retortillo:

«La posición que recojo lo es muy señaladamente frente a aquellos postulados metodológicos, conocidos, que tratan de convertir la Ciencia del Derecho en mero instrumento de la política económica; o, incluso, en mero instrumento de realización de distintos programas de actuación política, de los que con toda obviedad es preciso salvaguardar el entero sistema jurídico. Permanencia de las instituciones jurídicas; también, lógicamente, adaptabilidad de las mismas, con el fin de que asuman los cambios sociales y económicos correspondientes. Un esquema que, en sus términos más rigurosos, ha tenido y tiene validez general. La tiene, obviamente, en el campo del Derecho privado: leyes y códigos que son más que centenarios, cuando no instituciones y principios con muchos siglos de historia, continúan teniendo plena vigencia — vigencia social y no solo formal-. Y la tienen también en el campo del Derecho administrativo. Y ello, a pesar de la mayor sensibilidad y, también, del más directo condicionamiento que necesariamente presentan a circunstancias y principios sociales y políticos. Es fácil constatar a lo largo del tiempo la gradual aparición de técnicas e instituciones jurídico-administrativas diferentes, resultado muchas de ellas de ese proceso de adaptación de otras anteriores. Una realidad que expresa el dinamismo del propio Derecho, sin que se sea necesario cancelar ni arrumbar el sistema institucio-

${ }^{13}$ Vid. J. MeILÁn GIL, «El estudio de la Administración económica», loc. cit., p. 56 y S. MarTínRetortillo, Derecho Administrativo Económico, I, La Ley, Madrid, 1988, pp. 50 y ss. 
nal vigente so pretexto de dar entrada a categorías y conceptos más o menos novedosos ${ }^{14} \gg$.

Por otra parte, para la profesora Franch i SAGUER, la Administración económica se caracteriza porque la ordenación de la Economía se realiza a partir de la potestad reglamentaria, operándose una traslación de funciones del legislativo al ejecutivo. Las razones la profesora Franch i SAGUER las encuentra en que la Administración económica tiene una organización y composición más técnica y especializada que el poder legislativo y en que la necesidad de instrumentos jurídicos dinámicos para regular temas económicos requiere la intervención de un sujeto con dicha potestad y, no se puede olvidar que la Administración económica goza de estas capacidades ya que dispone de un procedimiento normativo corto y que permite la fácil modificación de las normas ${ }^{15}$. Otra característica de la Administración económica sería su clara especialización. Es decir, a través de la enorme avalancha de objetivos económicos que le son confiados a determinados órganos administrativos, la Administración tiene la posibilidad de conocer bien la realidad económica y, por tanto, de adaptar todo el conjunto de decisiones políticas a la realidad ${ }^{16}$. De ahí que el personal al servicio de la Administración económica debe ser cualificado.

Además, la Administración económica se ha caracterizado desde su nacimiento como una Administración negociada:

\footnotetext{
«El tema irrumpió en el campo del Derecho administrativo económico en los años sesenta de la mano de los planteamientos económicos en los años sesenta de la mano de los planteamientos que, en el contexto de la llamada «planificación a la francesa», se hicieron de la que se calificó como «economía concertada»; y también, «economía contractual». Aquélla, en expresión de F. BLOCH-Lainè, supone «un régimen de organización económica en la que los representantes del Estado... y los representantes de las empresas se reúnen organizadamente para intercambiar sus informaciones, confrontar sus previsiones y, conjuntamente, tomar decisiones unas veces, y otras, formular opiniones dirigidas al Gobierno». Enunciado de carácter general que muy pronto, transcendiendo el contexto concreto en que se recoge, el de la planificación económica, se proyectaría en determinadas instituciones jurídicas concretas: acción concertada, precios.
}

Concertación que en ocasiones se asume en el ámbito económico con carácter general (Pactos de Moncloa, AMI, AES, etc.). Lo así acordado, sin embargo, debe recibir posteriormente la oportuna formalización jurídica; también el desarrollo correspondiente. Y ello en los términos requeridos por el compromiso político que aquélla representa, y al que en todo caso debe adecuarse. Formalización que supone

\footnotetext{
${ }^{14}$ S. Martín-Retortillo, cit., p. 55.

${ }^{15}$ M. Franch i Saguer, op. cit., p. 60.

16 Ibidem.
} 
sancionar los criterios de la negociación como presupuesto del que se derivará la posterior actuación administrativa que, en definitiva, los hagan realidad ${ }^{17}$ ».

Las fuentes del Derecho administrativo económico se encuentran moduladas por la dinamicidad y discrecionalidad propias de una Administración que se caracteriza por la intervención en la Economía y por la emisión de normas que, más que obligar, tratan de dirigir las conductas económicas hacia los objetivos de política económica propuestos por el Gobierno.

Como es lógico, la fuente principal es la Constitución, ya que establece unos principios económico-sociales que delimitan el contenido de las normas económicas, conforma las figuras jurídicas que se utilizarán para regular las materias económicas y constituye el marco de las potestades legislativas y reglamentarias. Es claro que los objetivos, de la política económica que consideren preferentes los Poderes públicos, necesitan de instrumentos jurídicos que obliguen al ciudadano; instrumentos que pueden ser tanto formas normativas ya existentes, como formas jurídicas nuevas ${ }^{18}$.

Normalmente, la función de la ley en el marco del Derecho administrativo económico reside en trasladar derechos económicos de los particulares al ámbito del intervencionismo público. Pero la ley, además de servir de presupuesto para la Administración económica, también impone deberes al ciudadano en la medida en que participa en el proceso económico. En fin, en materia económica, la ley tiene un contenido muy limitado: fijar principios y habilitar a la Administración para que pueda posteriormente desarrollarlos. Ahora bien, el contenido de la ley es limitado en materia económica de manera que los reglamentos adquieren gran importancia, ya que al Gobierno - artículo 97 de la Constitución - le corresponde la dirección de la política económica. Lo normal, entonces, será que la ley fija unos principios y remite al reglamento para que los desarrolle.

Frente a los reglamentos, fuente característica del Derecho administrativo económico, debemos destacar un tipo de reglamento de especial relevancia en la materia que estudiamos: la denominada directriz que, en opinión de Franch i SAGUER, es el instrumento jurídico para llevar a cabo la política económica ya que la Economía exige instrumentos jurídicos específicos que permitan la concreción de la política económica.

Por lo que se refiere a la actividad administrativa económica, ésta se puede clasificar en actividades de dirección, actividad de incentivación y

\footnotetext{
${ }^{17}$ S. Martín-Retortillo, cit., pp. 58 y 59.

${ }^{18}$ M. Franch i Saguer, op. cit., p. 62.
} 
actividad de control. La actividad de dirección se refiere a individualizar los objetivos en el marco de la política económica; la actividad de incentivación es el conjunto de actos administrativos que, en el proceso económico, convierten en realidad los objetivos económicos — actividad de fomento - y, finalmente, actividad de control, como su propio nombre indica, se circunscribe a la verificación del cumplimiento de la regulación a la que está sometido el sector concreto de la actividad económica.

En fin, mucho es lo que debemos los administrativistas a Sebastián Martín-Retortillo. Pero, quizás, en materia de Derecho administrativo económico sus aportaciones han sido las más agudas y penetrantes. 